\title{
The macroeconomics of COVID-19: a two-sector interpretation*
}

\author{
Halvor Mehlum \\ Department of Economics, University of Oslo, Norway \\ Ragnar Torvik** \\ Department of Economics, Norwegian University of Science and Technology, Trondheim, Norway
}

For a developed market economy, the COVID-19 crisis is a new type of crisis, but such a crisis has parallels with economies at other times, and with crises in many places. We discuss some mechanisms from the traditional macro literature and from the literature on macroeconomics for developing countries. Phenomena such as bottlenecks, rationing, forced savings, production constrained by access to inputs, liquidity constraints, sector heterogeneity, and costs running despite production being shut down, are all permanent phenomena in developing countries. During the COVID-19 crisis, however, they have also emerged as key mechanisms in developed market economies. We discuss some of these well-developed but partially forgotten mechanisms by extending simple textbook descriptions, and we provide some examples of how the effects of policy are changed in a time of crisis.

Keywords: COVID-19 crisis, multi-sector macro model, demand and supply interactions

JEL codes: $B 22, E 12, E 62, E 65$

\section{INTRODUCTION}

Macroeconomists are struggling to come to grips with and provide a macroeconomic analysis of the COVID-19 pandemic. Currently, Keynesian-inclined economists have sought to explain the pandemic using the income-expenditure model, whereas mainstream economists have sought to explain the pandemic using the aggregate demand (AD)aggregate supply (AS) model. In the former, the pandemic takes the form of a pure negative $A D$ shock, whereas in the latter it takes the form of a joint negative shock to $A D$ and AS. This paper offers an alternative interpretation in terms of a Keynesian two-sector model.

No part of the economy escapes the macroeconomic consequences of COVID-19. Reduced production in one firm affects demand for other firms' products. Shortages in one sector lead to unemployment in other sectors. When supply is restrained in one sector it leads to reduced demand in other sectors.

* We are grateful for inspiring comments and constructive suggestions from editor Thomas Palley and co-editors Esteban Pérez Caldentey and Matías Vernengo. We have also received comments on these topics from Lars-Erik Borge, Stein Ove Erikstad, Rune Jansen Hagen, Torfinn Harding, Kalle Moene, and Øistein Røisland.

** Ragnar Torvik is also affiliated with the BI Norwegian Business School as Professor II at CAMP (Center for Applied Macroeconomics and Commodity Prices), Oslo, Norway. 
The two-sector model has a long and productive history in Keynesian macroeconomics. It has been used in an open-economy context to explain economic outcomes between countries (see Dornbusch 1980, ch. 3) and to explain spillovers between sectors in a multi-sector economy (see Palley 1990). It has also been applied to developing economies (see Taylor 1991). This paper applies the two-sector model to the COVID-19 pandemic, which is interpreted in terms of a sector-specific supply shock that spills over to the rest of the economy as a demand shock. Specifically, the pandemic can be interpreted as a shock to the services sector (for example, hotels, restaurants, travel, entertainment, etc.) with such activities being closed by law or by consumers refusing to congregate as needed to purchase such services.

\section{MACROECONOMICS, DEVELOPMENT ECONOMICS, AND RECENT MACRO THEORY}

Bottlenecks and forced savings are not standard building blocks in describing a modern capitalist economy. However, they are classic and important topics in economies at other times and in many places. In his book Economics of Shortage (1980), the Hungarian economist János Kornai described both types of mechanism in great detail. In his discussion of the problems of centrally planned economies, and in the article 'The measurement of shortage' (1976), he discusses in depth shortage-forced saving.

Shortages and rationing were also an important phenomenon in the war economies in the period 1940-1945. Rationing of goods contributed to high savings in the United States during the war. Private savings helped fund the war effort, but they also proved important when peace came. At the end of the war, there was great concern in the US about mass unemployment and downturns when the war industry shut down and when demobilized soldiers returned home. Later Nobel laureate Lawrence Klein (1964) was rather optimistic. His reasoning was that, as soon as rationing ceased, consumption, which had previously been kept down, would boom. His concept of this phenomenon was pent-up demand. Nobel laureate Trygve Haavelmo worked in the Cowles Commission with Klein towards the end of the war and the discussions about such deferred consumption and forced savings certainly inspired Haavelmo in the lectures on price control and rationing he held in 1956. In chapter 4 of From the Theory of Rationing and Price Regulation by Johansen (1958, p. 21), he notes the following (our translation from Norwegian): 'We can say that the difference between the expenditure for the originally intended quantity and the cost of the rationed quantity can be denoted as forced savings when your income is given.'

Also, in Structuralist equilibrium models for developing countries, scarcity appears as an important explanatory mechanism. This is based on a long tradition that studies how scarcity of goods restricts production and investment. Michał Kalecki (1971) was concerned that scarcity of agricultural goods limited industrial expansion, while Hollis Chenery was concerned with how scarcity of export revenue limited imports of necessary inputs and investment goods, thereby hampering growth (see for example Chenery and Bruno 1962). As the chief economist of the World Bank, Chenery in the 1970s used such reasoning as an argument for foreign aid. In Structuralist equilibrium models, this problem is sometimes referred to as import compression. In these models, prices are not able to balance supply and demand in all markets, and rationing has economy-wide effects. An example is Davies et al. (1994). In this description of Zimbabwe's economy, import compression leads both to lower investment and lower production. In addition, rationing of consumption goods increases private savings. 
Disequilibrium models were also central to macroeconomics for capitalist economies. Here, models were developed where prices did not adjust to achieve equilibrium in the markets, often referred to as fix-price models. These models may exhibit disequilibrium with rationing in some markets, for example in the labor market, while they can be at equilibrium in others. Barro and Grossman (1976), Malinvaud (1977), and Bénassy (1982) delivered important contributions to this area of macroeconomics, which is also very relevant during the COVID-19 crisis. $^{1}$

We also find similar mechanisms from the literature above in recent macroeconomic theory for developed market economies, albeit in models based on a somewhat different tradition. A dominant field of research is linked to so-called New Keynesian models, where the agents are assumed to be more rational and forward-looking than in traditional Keynesian models, but where there are nominal rigidities so that production is not always at its equilibrium level. Lately, these models have been modified to have some features that make them even more similar to the traditional Keynesian models. For example, under the assumption of imperfect credit markets, consumption will not depend on permanent income and real interest rates only, because some consumers will be rationed and only consume current income. From this assumption, it follows directly that current income also plays a role in aggregate demand. See, for example, Debortoli and Galí (2018) and Kaplan et al. (2018).

There are also examples of recent macro models that directly study the effects of the COVID-19 crisis, although none of these, as far as we have seen, point out that the mechanisms discussed are very similar to those previously studied in the macro literature of developing countries. The paper that most closely resembles ours is Guerrieri et al. (2020). These authors show that several of the results that we find in our simple model can also be valid in more recent types of macro models, as long as these are extended to allow for more than one sector.

In the following, we aim to discuss how some of the mechanisms from traditional macro literature, from development economics and also from more recent macro literature, can impact the economy and economic policy in the time of COVID-19. We have chosen to do this by extending well-known model frameworks. This, hopefully, makes the analysis also available to students and to economists who do not have macroeconomics as their research field.

However, our choice of model framework comes at a cost. The literature referred to is much richer in mechanisms than the ones we address. And our presentation of the mechanisms, embedded in well-known frameworks, does not do justice to the literature. In addition, we look at economics and politics during the crisis. Mechanisms that are relevant in the longer term - that is, after the crisis - may be different and are not addressed here. Particularly important are hysteresis effects. If the crisis is deep and long-lasting, it can be very difficult to avoid having permanent effects in the form of lower production and higher unemployment. The steady state of an economy is not something that should be viewed as exogenous, as much of current macro theory implicitly assumes when focusing on fluctuations around a given steady state.

1. It may be in order to include a critical note to some of the literature referred above. In both structural equilibrium models and fix-price models, it can sometimes be difficult to see what role prices really play, as well as how the agents influence them. However, this literature shares this feature with much of the macro theory that dominates the profession today, where, for example, it is often exogenously assumed that only a fraction of firms can change prices at any given time. 
In order to discuss how the crisis affects demand and supply, we use the simplest Keynes model, and show how this can be modified by incorporating crisis mechanisms. We then use this modified model to discuss the impact of fiscal policy during the crisis.

\section{A SIMPLE MODEL IN THE TIME OF COVID-19}

We start from the premise that during the time of COVID-19, government restrictions constrain the production of some goods and services. These goods and services are limited from the supply side, while others may be limited from the demand side. We let $Y_{2}$ denote the total production of goods and services that are directly affected by virus prevention measures (full or partial), while $Y_{1}$ is the production of goods and services not directly affected by prevention measures. ${ }^{2}$ For ease of exposition, we refer to $Y_{1}$ as goods and $Y_{2}$ as services. In order to keep things simple, we abstract from intermediate deliveries between sectors. This is innocuous as long as we assume that only final deliveries are directly affected by government restrictions. ${ }^{3}$

Total private disposable income is $(1-t)\left(Y_{1}+Y_{2}\right)$, where $t$ is a tax rate. Out of this the households want to consume a fraction $c<1$. We let $(1-f)$ be the proportion of consumer demand directed towards goods, while the proportion $f$ is directed towards services. We also make a similar distinction between two categories of investment goods, $I_{1}$ and $I_{2}$, and two categories of public spending, $G_{1}$ and $G_{2}$, and net exports, $N X_{1}$ and $N X_{2}$. In the time of COVID-19, a fraction of consumer demands cannot be realized due to supply constraints and we let the parameter $q$ capture the fraction of services that is restricted. The restriction parameter $q$ represents services such as air travel and cultural services that have been eliminated from the supply. We leave $c$ and $f$ unchanged and then implicitly follow Kornaí's idea of 'forced saving,' assuming that consumption of the goods that have become unavailable will cease if there are no immediate alternatives. Then only a fraction $(1-q)$ of the consumption demand directed towards services is effectuated. Combining all of this, we get the two relationships for demand towards each sector:

$$
\begin{gathered}
Y_{1}=(1-f) c(1-t)\left(Y_{1}+Y_{2}\right)+I_{1}+G_{1}+N X_{1} \\
Y_{2}=(1-q) f c(1-t)\left(Y_{1}+Y_{2}\right)+I_{2}+G_{2}+N X_{2},
\end{gathered}
$$

where the first term on the right-hand side of the equations represents consumer demand, and the rest of the variables are other demand components directed towards the relevant sector. ${ }^{4}$

2. The closure can be caused both by direct infection control, as for hairdressers, and as an indirect consequence of the stopping of critical parts of the production chain, such as for goods dependent on air transport.

3. To the extent that intermediate deliveries are also affected, downstream goods will also be among goods that are restricted in supply. Such interlinkages could be included at the expositional cost of making the graphical analysis more complicated.

4. It is far from certain that these other demand components are each proportional to $f$. Net exports are particularly interesting. Overseas holiday travel can be an important import component of consumption. The net export of holidays can therefore be large and negative. Such factors must be taken into account when total net exports are distributed between sector 1 and sector 2 . 
We now solve with respect to the production in each sector, so that equations $\left(1^{\prime}\right)$ and $\left(2^{\prime}\right)$ can be written as:

$$
\begin{gathered}
Y_{1}=\frac{1}{1-(1-f) c(1-t)}\left((1-f) c(1-t) Y_{2}+I_{1}+G_{1}+N X_{1}\right) \\
Y_{2}=\frac{1}{1-f(1-q) c(1-t)}\left(f(1-q) c(1-t) Y_{1}+I_{2}+G_{2}+N X_{2}\right) .
\end{gathered}
$$

When $q=0$, these equations are shown in Figure 1 as the solid curves denoted, respectively, as $D_{1}$ and $D_{2}$. Hence, without supply restrictions, the solution is $Y_{1}^{0}, Y_{2}^{0}$ and overall production $Y^{0}=Y_{1}^{0}+Y_{2}^{0}$ is

$$
Y^{0}=\frac{1}{1-c(1-t)}\left(I_{1}+I_{2}+G_{1}+G_{2}+N X_{1}+N X_{2}\right),
$$

which is exactly what would be inferred in a one-sector description of the economy. The two curves show the interdependence between the sectors. An exogenous drop in demand towards one sector will spill over to the other and will generate demand repercussions between the two sectors. The total effect, absent restrictions, of an exogenous demand shock is captured by the multiplier in equation (3). Lowering demands towards one sector lowers production in both. There are indirect demand effects that suppress production in both sectors. The reason is that the two sectors are in a complementary relationship with each other, where income in one sector provides demand for the other. It is this total effect that the multiplier in equation (3) captures. One sector is dependent on consumer demand from the other, and vice versa. This feature has links to another classic in development economics, namely Rosenstein-Rodan's big push mechanism. In the descriptions by Rosenstein-Rodan (1943) and Nurkse (1952), the different sectors depend on each other's demand to generate profits.

With some degree of supply restrictions, $q>0$, the solution for $Y$ is

$$
Y=\frac{1}{1-c(1-t)(1-q f)}\left(I_{1}+I_{2}+G_{1}+G_{2}+N X_{1}+N X_{2}-\Delta\right),
$$

where $\Delta$ captures exogenous demand effects as a result of COVID-19. Going from $q=0$ to a case with positive $q$ lowers the multiplier and reduces overall production for given exogenous demand.

This is also illustrated in Figure 1. Here, a $q$ larger than zero is captured by the curve $D^{\prime}{ }_{2}$. An increase in $q$ makes part of the consumption demand directed towards services unsatiated. As a result, the activity in services drops. The services sector is now partly supply-constrained. The immediate consequence of the supply constraint is that production of services drops from the initial equilibrium. When demand repercussions within services is also accounted for, it leads to a drop down to point $\mathrm{A}$ in the figure. This vertical distance is a measure of the extent of supply constraints in services, when demand repercussions via the goods sector is not accounted for. But lower activity in services lowers demand towards goods. Due to demand multipliers, goods production shrinks further down to the new equilibrium where both $Y_{1}$ and $Y_{2}$ are lower. The new equilibrium is point $\mathrm{B}$ at the intersection of the $D_{2}^{\prime}$ and $D_{1}$ curves.

Hence, services is hit twice. First, as parts of it are shut down. Second, as the economy contracts, the services that still operate suffer a demand contraction. The demand 


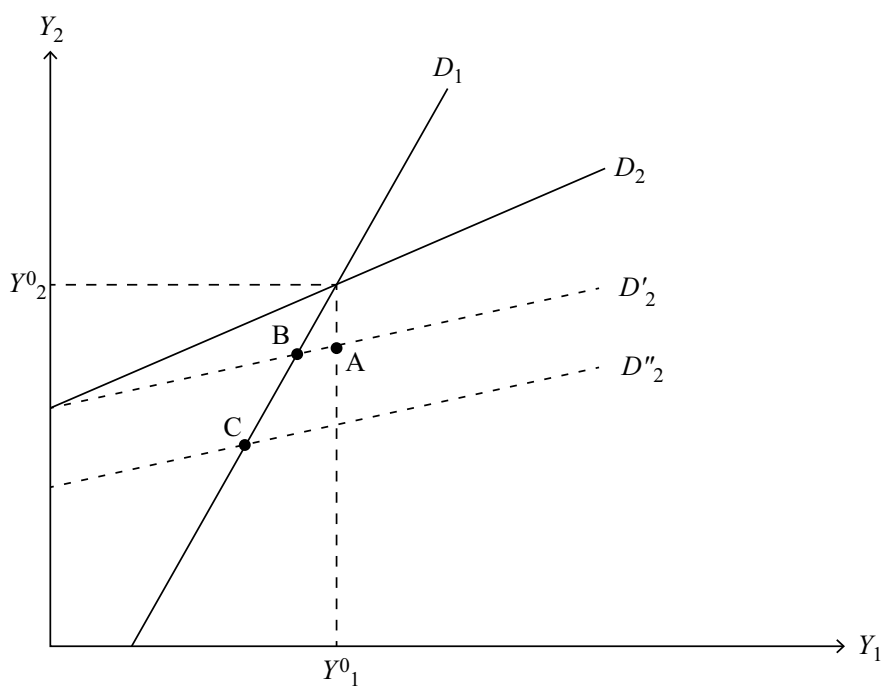

\section{Figure 1 Partial COVID-19 shut down of sector 2}

repercussions to services via the goods sector is less than in the unconstrained case, however, as can be seen from (2), the slope of $D^{\prime}{ }_{2}$ is less than the slope of $D_{2}$. Hence, services production reacts less to the drop in goods production when some services cannot be delivered. ${ }^{5}$

As we have seen, the drop in aggregate income exceeds the drop in income due to the restrictions in services. Guerrieri et al. (2020) define a supply shock that decreases aggregate production by more than the shock itself as a 'Keynesian supply shock.' Of course, in development economics such a result is rather standard, for instance, with a drought, aggregate production drops by more than the fall in agricultural output.

In addition, the supply constraints may affect other demand components as well. $N X_{2}$ and $I_{2}$ may drop as service supply for these purposes is halted, or because the crisis has additional effects on demand to those analysed above. The effect of such drops is captured by the variable $\Delta$ and is represented in Figure 1 by the vertical shift from $D^{\prime}{ }_{2}$ to $D^{\prime \prime}{ }_{2}$. In this case the new equilibrium ends up in $\mathrm{C}$ at the intersection of the $D^{\prime}{ }_{2}$ and $D_{1}$ curves. Also in this case there are multiplier effects between the sectors.

In this equilibrium, production is lower than at the outset. The output gap $u$ resulting from COVID-19 restrictions can be defined as

$$
u=\frac{Y^{0}-Y}{Y^{0}} .
$$

5. This feature distinguishes our model from other two-sector descriptions of interaction between supply- and demand-determined sectors. In Palley (1990) for example, a sector is either fully supply-constrained or fully demand-constrained. If we introduced a complete supply constraint for services, $D_{2}$ would get a kink and become horizontal where the supply constraint starts to bind. In such a case we would not get the subsequent demand repercussions involving services. 
Assuming that labor use is proportional to production, the output gap is equivalent to unemployment, and inserting from equations (3) and (4) above and setting $\Delta=0$, $u$ can be written as

$$
u=\frac{(1-t) c q f}{1-(1-t) c(1-q f)}
$$

Here, $(1-t) c q f$ can be interpreted as the output gap following from the first round of contraction of sector 2 . The multiplier in the expression is an unemployment multiplier which is always greater than unity. The increase in unemployment thus comprises the direct effect in sector 2, multiplied by the unemployment multiplier.

So far, we have focused on the shutdown of parts of sector 2 and its impact on income and consumption demand. Investments can also be expected to be hit hard. The reason is that investments are complex activities where each project requires input from both sectors. If there is such a strong complementarity, we get the classic problem of developing countries, where investment will be paralysed by certain essential goods or components not being available. Often, the restriction is linked to the investor's access to currency. When there is such a strong complementarity between the elements, the shutting down of parts of sector 2 may completely end all investment demand directed towards sector 1 . The ability to invest is gone at the same time as the desire to invest is reduced. This represents a demand shock that hits the remaining activity in sector 1 hard. It comes at the top of the mechanisms via consumer demand and multipliers, and provides a further need for public countermeasures.

\subsection{What can be achieved with fiscal policy?}

The new economic situation has, as we have seen, reduced production through lower supply and demand in one sector and through lower demand in the other sector. What can be achieved with fiscal policy depends not only on the size of the contraction of the economy, but also on the situation the economy finds itself in before COVID-19. In general, if the economy is in a demand-constrained equilibrium before the crisis, then fiscal policy has the potential to do more than if the economy finds itself in a supplyconstrained equilibrium. As a reference, we can consider the case where the economy was in equilibrium before the pandemic, with full utilization of capital and labor in both sectors. This means that a policy aimed at compensating for the loss of demand with increased demand directed at sector 1, so that we again get full employment in the economy as a whole, cannot succeed. Employment can only increase in sector 1 as long as there is idle production capacity in the sector, that is, only sector 1 can be brought back to the pre-crisis level. ${ }^{6}$

This situation again has clear parallels to studies of developing economies. Expansive fiscal policy does not raise agricultural production when it is determined by the weather. It does not bring up production in manufacturing when it is restricted by access to imported inputs, or, as in our case, when production is halted for infectious disease protection.

6. Strictly speaking, this sentence is only valid in a case without substitution between labor and capital in sector 1. During the COVID-19 crisis, in the short run, it seems like a reasonable assumption as in a simple way it captures the feature that it is difficult for sector 1 to absorb all labor that is vacant in sector 2 . 


\subsubsection{Demand stimulus}

In order to simplify the discussion, we look at the case where $q=1$. The results we derive can quite easily be extended to intermediate levels of $q$.

When sector 2 is closed down entirely, this sector will no longer be part of the economic loop. As we saw above, stimulus of sector 1 will be stronger when the effects via sector 2 are active. If sector 1 is already at full capacity the most expansive effect one can hope for, with demand stimulus, is to eliminate the decline in production due to a lower demand from sector 2 . From equation ( $\left.1^{\prime}\right)$ we see that the COVID-19 effect is captured by the $Y_{2}$ term. If this demand can be replaced by alternative demand, then production in sector 1 can be kept unchanged. This is the highest level of production that can be achieved by demand stimulus. If we denote this demand increase by $D^{k}$, then we see from $\left(1^{\prime}\right)$ that it is given by

$$
D^{k}=(1-f) c(1-t) Y_{2}^{0}
$$

This term is equivalent to consumer demand towards sector 1 from those previously earning their income in sector 2. A demand stimulus to compensate for the loss of this demand can be designed in several ways.

First, suppose that a lump-sum transfer is given to consumers, which we designate by $S^{k}$. Since only a fraction, given by $(1-f) c(1-t)$, of this transfer generates demand for sector 1 , we have that

$$
S^{k}=Y_{2}^{0}
$$

Should increased demand be achieved with such a grant, it is required that the amount is equal to the entire production decline in sector 2 . Some of this amount is, however, recovered via public-sector tax income $t S^{k}$, so the net outlay is $(1-t) S^{k}$.

If demand stimulus is instead achieved through increased government purchases of goods and services towards sector 1 , the required increase in $G_{1}$ is given by

$$
(1-f) c(1-t) Y_{2}^{0}<(1-t) S^{k} .
$$

Behind this is a well-known result, as well as a COVID-19-specific mechanism. The well-known result, established by Haavelmo (1945), is that public purchases have a stronger impact on demand than transfers to the private sector. The reason is that the entire public purchase contributes to increased demand, while only a share $c$ of net cash support $(1-t) S^{k}$ contributes to increased demand. The COVID-19-specific mechanism is that this difference in the effectiveness of the two policy instruments in influencing demand is reinforced during the crisis. The intuition for this is that more than a usual transfer is saved because some goods are not possible to buy. This effect is represented by the term $(1-f)$. The relative difference in the efficiency of public demand directly to sector 1, compared to a general tax cut, is thus that public purchases are $1 /[(1-f) c]$ times as efficient. This ratio was in Haavelmo (1945) as $1 / c$. In a numerical example where $c=0.7$ and $f=0.3$ then the Haavelmo result is twice as strong in COVID-19 times compared to normal times. The larger the part of the economy that is hit by the shutdown, the less efficient are the tax cuts relative to public purchases of goods and services in affecting total production.

The analysis above does not, however, take into account that the behavior of the individuals directly affected by the shutdown may be different compared to those not affected by the shutdown. The income of the unemployed is lower than the income 
of those still in employment. It is reasonable to expect that the consumption propensity of those affected is higher than that of those who are not affected (as in Taylor 1991). Targeted transfers to those affected can then provide both more efficient demand stimulus and a more equitable distribution of the burden of closure than a general tax cut would provide. If the propensity to consume sector 1 goods for those directly affected is not $(1-f) c$, but rather is 1 , then targeted transfers are as effective as public purchases of goods and services in influencing demand. Thus a variant of Haavelmo's result is that general taxes that fund targeted transfers to those affected by the shutdown will be expansionary without weakening the government budget.

\section{CONCLUDING REMARKS}

In the analyses above, where there is full employment and capacity utilization before the crisis occurs, it is impossible for the policy to ensure balance in the economy when the crisis occurs. No matter how powerful the sum of fiscal and monetary policies is, the decline in activity levels and the rise in unemployment cannot be fully offset. The reason is that part of the economy is directly restricted from the supply side by political decisions motivated by limiting the spread of the virus. The best one can achieve, as regards stabilization policy, is to correct for the indirect demand and supply effects.

In a time of crisis, it may make sense for economists to supplement the model types they usually work with. For developed market economies, there may be much to learn from economies in crisis at other times and in other places. Both historical analyses of non-market economies, and analyses that study economic mechanisms in developing countries, contain well-developed insights for analysing the crisis we are in, as well how economic policy may work during such a crisis. It is easy to become too preoccupied with the most recent advances in economic models, and to get too caught up in the present consensus. But it is also important to look for established insights that have proven relevant in similar crisis situations. We should recognize that analyses that the economics mainstream profession do not usually see as relevant can bring lessons into a new, and for the mainstream economic profession, unfamiliar time.

\section{REFERENCES}

Barro, R.J. and H.I. Grossman (1976), Money, Employment and Inflation, Cambridge, UK: Cambridge University Press.

Bénassy, J.-P. (1982), The Economics of Market Disequilibrium, New York: Academic Press.

Chenery, H.B. and M. Bruno (1962), 'Development alternatives in an open economy: the case of Israel,' The Economic Journal, 72, 79-103.

Davies, R., J. Ratts $\varnothing$, and R. Torvik (1994), 'The macroeconomics of Zimbabwe in the 1980s: a CGE-model analysis,' Journal of African Economies, 3(2), 153-198.

Debortoli, D. and J. Galí (2018), 'Monetary policy with hetrogenous agents: insights from TANK models,' Uupublished Working Paper, Barcelona: CREi.

Dornbusch, R. (1980), Open Economy Macroeconomics, New York: Basic Books.

Guerrieri, V., G. Lorenzoni, L. Straub, and I. Werning (2020), 'Macroeconomic implications of COVID-19: can negative supply shocks cause demand shortages?,' Unpublished Working Paper, Cambridge, MA: MIT.

Haavelmo, T. (1945), 'Multiplier effects of a balanced budget,' Econometrica, 13, 311-318.

Johansen, T. (1958), Fra teorien om rasjonering og prisregulering, Utarbeidet på grunnlag av notater fra professor Haavelmo's forelesninger våren 1956, Memorandum 12.12.1958. 
174 Review of Keynesian Economics, Vol. 9 No. 2

(Translation: From the Theory of Rationing and Price Regulation, Developed from the background of notes from Professor Haavelmo's lectures in the spring of 1956.)

Kalecki, M. (1971), Selected Essays on the Dynamics of the Capitalist Economy, Cambridge, UK: Cambridge University Press.

Kaplan, G., B. Moll, and G.L. Violante (2018), 'Monetary policy according to HANK,' American Economic Review, 108, 697-743.

Klein, L. (1964), 'The Keynesian revolution revisited,' The Economic Studies Quarterly, XV(November), 1-24.

Kornai, J. (1976), 'The measurement of shortage,' Acta Oeconomica, 16(3-4), 321-344.

Kornai, J. (1980), Economics of Shortage, Amsterdam: North Holland Press.

Malinvaud, E. (1977), The Theory of Unemployment Reconsidered, Oxford: Blackwell.

Nurkse, R. (1952), 'Some international aspects of the problem of economic development,' American Economic Review, 42, 571-583.

Palley, T.I. (1990), 'Applied fix-price macro models: a reconsideration,' Atlantic Economic Journal, 18(2), 1-16.

Rosenstein-Rodan, P.N. (1943), 'Problems of industrialisation of Eastern and South-Eastern Europe,' The Economic Journal, 53, 202-211.

Taylor, L. (1991), Income Distribution, Inflation, and Growth: Lectures on Structuralist Macroeconomic Theory, Cambridge, MA: MIT Press. 